\title{
Correspondence If Intergenerational Transmission Is the Problem, Then What Is the Solution?
}

\author{
Marek S Kopacz ${ }^{*, 1}$ and Craig J Bryan ${ }^{2}$ \\ 'US Department of Veterans Affairs, VISN 2 Center of Excellence for Suicide Prevention, Canandaigua, NY, USA; ${ }^{2}$ The University of Utah, National \\ Center for Veterans Studies, Salt Lake City, UT, USA
}

Neuropsychopharmacology (2016) 4I, 2965; doi:I0.1038/npp.2016.23

In their exhaustive review, Bowers and Yehuda (2015) examine the intergenerational transmission of stress in humans. Although research in this field has been ongoing for many years, Bowers and Yehuda (2015) note, our understanding of this problem is just starting to emerge. As such, would it perhaps be prudent to expand the conversation? Just as we look to understand the intergenerational transmission of stress, so too should we be looking for ways to break this cycle.

For example, throughout their paper, Bowers and Yehuda (2015) highlight the intergenerational burden of posttraumatic stress disorder (PTSD). Could they be signaling a potentially serious public health problem for the coming years? As the United States continues to withdraw from foreign theaters of combat, it is reasonable to expect an increase in the number of veterans who experienced traumatic stress during military service. In FY2011, 476515 veterans received services related to the diagnosis of PTSD at US Department of Veterans Affairs health-care facilities (US Department of Veterans Affairs, 2014).

The question remains if effectively treating PTSD in this generation can help prevent untoward consequences in the next generation. Unfortunately, even after psychotherapy, many current and former military personnel continue to meet diagnostic criteria for PTSD (Steenkamp et al, 2015). While this highlights an urgent need for innovative treatment options, it also underscores the need for changing the conversation of intergenerational transmission, to include not just stress but also resilience.

Bowers and Yehuda (2016) hypothesize that PTSD 'manifest[s] from a deficit in the ability to shift behavior in response to changing contexts' ( $p$ 242). If we enhance the ability of our veterans to shift their behavior in response to traumatic stress, could we also enhance this ability in the next generation? Different developmental theories appear to speak in favor of such reasoning (eg, Callaghan et al, 2013; Feder et al, 2009).

*Correspondence: Dr M Kopacz, US Department of Veterans Affairs, VISN 2 Center of Excellence for Suicide Prevention, 400 Fort Hill Avenue, Canandaigua, NY 14424, USA, Tel: +I 585393 767I, E-mail: marek.kopacz@va.gov
A number of long-term longitudinal projects examining veteran health outcomes are currently underway. Further, a number of well-developed mental health support options exist for veterans and their families. In many ways, this has created a solid foundation for examining intergenerational outcomes, inclusive of the transmission of stress as well as resilience. Of note is that most PTSD studies focus only on outcomes of the individuals receiving the treatment. If true, we foresee the intergenerational transmission of resilience as also being an important tool for addressing mental health stigma. Where service members and veterans may not be inclined to seek treatment for themselves, perhaps they would be willing to seek out treatment for the benefit of their children and grandchildren. Understanding the solution is just as important as understanding the problem.

\section{FUNDING AND DISCLOSURE}

The author declares no conflict of interest.

\section{DISCLAIMER}

The views expressed are those of the author and do not reflect the official policy or position of the Department of Veterans Affairs (VA) or the US Government.

\section{REFERENCES}

Bowers ME, Yehuda R (2016). Intergenerational transmission of stress in humans. Neuropsychopharmacol Rev 41: 232-244.

Callaghan BL, Graham BM, Li S, Richardson R (2013). From resilience to vulnerability: mechanistic insights into the effects of stress on transitions in critical period plasticity. Front Psychiatry 4: 90.

Feder A, Nestler EJ, Charney DS (2009). Psychobiology and molecular genetics of resilience. Nat Rev Neurosci 10: 446-457.

Steenkamp MM, Litz BT, Hoge CW, Marmar CR (2015). Psychotherapy for military-related PTSD: a review of randomized clinical trials. JAMA 314: 489-500.

US Department of Veterans Affairs (2014). Veterans posttraumatic stress disorder (PTSD) http://www.va.gov/opa/issues/ptsd.asp. 